\title{
МЕНОПАУЗА: НОВЫЙ ВЗГЛЯД НА СТАРУЮ ПРОБЛЕМУ
}

$\mathrm{H}$ есмотря на значительное количество исследований, посвященных здоровью женщин старше 50 лет, проблема лечения климактерических расстройств и сегодня чрезвычайно актуальна, потому что касается в первую очередь качества жизни женщин в период их профессиональной зрелости и наибольшей востребованности в обществе и семье. Увеличение продолжительности жизни и продление возраста трудоспособности приобретают не только медицинское, но и социально-экономическое значение как в нашей стране, так и в других развитых странах. По прогнозам ВО3, к 2015 г. 46\% женщин на планете будут в возрасте старше 45 лет (пери- и постменопаузальный периоды), среди женщин Украины - это почти половина (13,2 млн) [1-3].

Как известно, в менопаузе в организме женщины происходит стремительное снижение синтеза половых гормонов, развивающееся в результате инволютивных процессов в репродуктивной системе, с чем и связано появление разнообразной клинической симптоматики. Именно наличием эстрогеновых рецепторов в различных органах и системах (матке, яичниках, молочных железах, центральной и периферической нервной системе, сердце, сосудах, мочеточниках, мочевом пузыре, костной ткани, кишечнике и в других органах) обусловлено разнообразие симптоматики климактерического синдрома. В первую очередь появляются приливы жара, повышенная потливость, лабильность артериального давления, сердцебиение, онемение частей тела, эмоциональная лабильность, плаксивость, угнетенное настроение, нарушение сна, другие вегетативные и психоэмоциональные расстройства, которые и объединяют понятием «климактерический синдром» [3-5].

Дефицит эстрогенов может привести к возникновению серьезных метаболических нарушений в различных органах и системах с возможным последующим развитием ряда заболеваний (остеопороза, кардиоваскулярной патологии, болезни Альцгеймера и др.) $[5,6]$.

Учитывая мультидисциплинарность проблемы, существует масса дискутабельных и часто необоснованных подходов к лечению данной категории пациенток. Именно заместительная гормональная терапия (ЗГТ) остается стандартом терапии и главным патогенетически обоснованным медикаментозным методом лечения климактерических нарушений $[7,8]$.
Последние данные о пользе и рисках применения ЗГТ были представлены в Риме на 13-м Всемирном конгрессе по менопаузе (2011), а именно обновленная версия Рекомендаций Международного общества менопаузы по использованию ЗГТ. В Рекомендациях под термином «заместительная гормональная терапия» подразумеваются виды терапий с использованием эстрогенов, прогестагенов, комбинаций препаратов, андрогенов и тиболона [8].

Основные принципы Рекомендаций Международного общества менопаузы по использованию ЗГТ включают в себя:

? раннее начало применения 3ГТ;

7 хороший профиль безопасности ЗГТ в случае ее назначения женщинам моложе 60 лет;

7 женщинам, находящимся на ЗГТ, следует, как минимум, один раз в год проходить обследование у гинеколога со скрининговым анализом мазка из шейки матки и маммографическое обследование, при необходимости проводить консультации смежных специалистов;

7 дозу ЗГТ следует титровать до наименьшей эффективной. Более низкие дозы ЗГТ, чем те, которые использовались ранее, могут в достаточной мере смягчать симптомы и поддерживать качество жизни у многих женщин;

? пациенткам с сохраненной маткой к системному эстрогену необходимо добавлять прогестерон, чтобы предотвратить гиперплазию и рак эндометрия. Кроме ожидаемого действия на эндометрий прогестагены могут отличаться по своему возможному неблагоприятному влиянию на метаболизм или ассоциированному риску развития рака молочной железы при сочетании с терапией эстрогенами в течение длительного времени.

\section{ЗГТ КАК ПРОФИЛАКТИКА И ЛЕЧЕНИЕ РАЗЛИЧНЫХ НАРУШЕНИЙ}

Риски и польза ЗГТ отличаются у женщин в период перехода к менопаузе и у женщин более старшего возраста. У женщин со спонтанной или ятрогенной менопаузой в возрасте до 45 лет (особенно до 40 лет) повышается риск развития сердечно-сосудистых заболеваний (С33), остеопороза, аффективных расстройств и деменции. Поэтому им рекомендуется продолжать гормональную терапию по меньшей мере до достижения среднего возраста возникновения менопаузы.

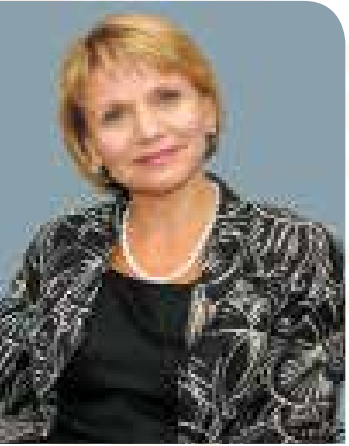

Т.Ф. ТАТАРЧУК д.мед.н., просрессор, член-корр. НАМН Украины, заместитель директора по научной работе, заведующая отделением эндокринной гинекологии Института педиатрии акушерства и гинекологии НАМН Украины

О.А. ЕФИМЕНКО к.мед.н., старший научный сотрудник отделения эндокринной гинекологии Института педиатрии, акушерства и гинекологии НАМН Украины

А.О. ИСЛАМОВА к.мед.н., отделение эндокринной гинекологии Института педиатрии, акушерства и гинекологии НАМН Украины 


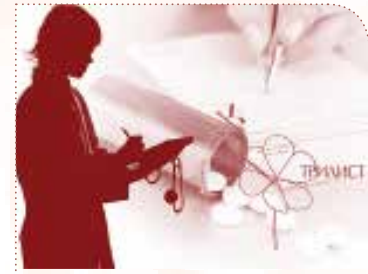

ЗГТ эффективно предотвращает потерю костной ткани, связанную с наступлением менопаузы, и снижает частоту всех переломов, связанных с развитием остеопороза, в том числе по звонков и бедра, даже у женщин, которым не угрожает повышенный риск переломов
Следует отметить доказанное положительное влияние ЗГТ при эстрогендефицитных постменопаузальных нарушениях, а именно при вазомоторных симптомах и атрофии органов мочеполовой системы. Также на фоне гормональной терапии возможно улучшение других обусловленных менопаузой нарушений, таких как боль в суставах и мышцах, перепады настроения, нарушения сна, половая дисфункция (в том числе снижение либидо).

ЗГТ, назначенная приблизительно в начале менопаузы или у женщин более молодого возраста в постменопаузе, сопровождается меньшим риском болезни Альцгеймера.

\section{Кардиоваскулярная патология}

Если говорить о профилактике СС3 как основной причины заболеваемости и смертности женщин в период менопаузы, то основными первичными профилактическими мерами являются снижение массы тела, нормализация артериального давления, регулярные физические упражнения, контроль за уровнем сахара и уровнем липидов. ЗГТ обладает способностью снижать риск развития СС3 благодаря положительному действию на функцию сосудов, уровни холестерина, метаболизм глюкозы и артериальное давление [9].

Имеются данные о том, что если терапию эстрогенами назначить приблизительно в начале менопаузы и продолжать в течение длительного периода, то она может оказывать кардиозащитное действие - снижает уровень липопротеинов низкой плотности (ЛПНП), повышает содержание липопротеинов высокой плотности (ЛПВП); усиливает вазодилатацию путем повышения уровня NO и индукции NOS-генов; уменьшает воспаление путем повышения уровня NO, снижения синтеза молекул клеточной адгезии, белка хемоаттрактанта моноцитов, фактора некроза опухоли; снижает уровень фибриногена, увеличивает фибринолиз путем снижения активности ингибитора активатора плазминогена-1 и повышения уровня D-димера [10-12]. Гестагены также оказывают кардиопротективный эффект, однако не все. Кардиозащитным действием обладает дидрогестерон - синтетический аналог натурального прогестерона, который не только не влияет на концентрацию триглицеридов, но и снижает уровень общего холестерина в среднем на 7\% в год, ЛПНП на $15 \%$ и повышает содержание ЛПВП на $12 \%$ в год. При сравнительном анализе данных UK General Practice Research Database $(n=69$ 412) использование эстрадиола/дидрогестерона от нескольких месяцев до нескольких лет не связано с повышением риска ССЗ по сравнению с отсутствием 3ГТ [1, 7, 8].
У женщин в возрасте до 60 лет, у которых менопауза началась недавно и не выявлено признаков СС3, инициация ЗГТ не вызывает ранних неблагоприятных последствий и может снизить заболеваемость и смертность от ишемической болезни сердца. Решение о продолжении ЗГТ после 60 лет должно быть принято с учетом общей оценки соотношения польза-риск.

При начале 3ГТ у женщин старшего возраста или тех, у кого с момента наступления менопаузы прошло более 10 лет, возможно повышение риска СС3, преимущественно в первые 2 года применения. Поэтому начинать ЗГТ у женщин старше 60 лет только с целью первичной профилактики ишемической болезни сердца не рекомендуется. Также считается, что нецелесообразно назначать ЗГТ женщинам старшего возраста с коронарными заболеваниями, принимающим терапию по стандартным терапевтическим схемам. Это же доказывает Исследование здоровья медицинских сестер (Nurses' Health Study, 1994), а именно: выраженность защитного влияния эстрогенов значительно выше у женщин с исходно высоким риском ССЗ. Эстрогены оказывают долговременное положительное влияние, сохраняющееся 1-2 года после прекращения лечения, однако затем ослабевающее. У пациенток с повышенным риском СС3 3ГТ не должна заменять традиционную терапию, назначаемую кардиологами-терапевтами.

\section{Остеопороз}

ЗГТ эффективно предотвращает потерю костной ткани, связанную с наступлением менопаузы, и снижает частоту всех переломов, связанных с развитием остеопороза, в том числе позвонков и бедра, даже у женщин, которым не угрожает повышенный риск переломов.

ЗГТ благоприятно влияет на состояние соединительной ткани, кожи, суставов и межпозвонковых дисков.

\section{Эндокринные нарушения}

Проблема метаболического синдрома в менопаузе очень важна и связано это с тем, что быстрая прибавка массы тела в перименопаузе отмечается примерно у 60\% женщин. По данным Исследования здоровых женщин (Healthy Women's Study), в первые 3 года после менопаузы масса тела увеличивается в среднем на 2,3 кг (у 20\% женщин - на 4,5 кг и более), а через 8 лет - на 5,5 кг [8, 9]. Один из механизмов влияния половых стероидов на жировую ткань - это прямая регуляция активности липопротеинлипазы. Эстрогены стимулируют липопротеинлипазу в жировой ткани бедер и ягодиц, где активность указанного фермента 
выше, чем в абдоминальном отделе, угнетают синтез нейропептида Y (при дефиците естрогенов концентрация последнего повышена, что способствует усилению аппетита и гиперфагии); воздействуют непосредственно на вентромедиальную область гипоталамуса и тем самым подавляют аппетит; регулируют продукцию лептина по принципу положительной обратной связи; подавляют синтез тирозингидроксилазы, участвующей в образовании катехоламинов; увеличивают плотность и функцию $a_{2}$-рецепторов на адипоцитах. После менопаузы активность липопротеинлипазы снижается, и периферические адипоциты уменьшаются в размерах, то есть происходит относительное перераспределение жира. Прогестерон также оказывает влияние на жировую ткань, конкурируя с глюкокортикоидами за их рецепторы в адипоцитах, и, соответственно, предотвращая воздействие глюкокортикоидов на жировую ткань в поздней лютеиновой фазе цикла. Было проведено масштабное исследование в рамках влияния ЗГТ на массу тела, в котором на протяжении 24 мес. назначался фемостон (препарат ЗГТ). В итоге было установлено, что назначение фемостона препятствовало развитию ожирения по андроидному типу $[3,7,8]$.

ЗГТ снижает риск развития сахарного диабета, улучшая действие инсулина у женщин с резистентностью к инсулину, оказывает благоприятное воздействие на прочие сопутствующие факторы риска ССЗ, такие как профиль липидов и метаболический синдром [13].

\section{ЗГТ и мочеполовая система}

Системная ЗГТ и особенно локально применяемые эстрогены могут скорректировать изменения в мочеполовом тракте, обусловленные недостаточностью эстрогенов, и поддержать влагалище в здоровом состоянии.

Отдельно бы хотелось остановиться на чрезвычайно актуальной проблеме у женщин в постменопаузе - вагинальной атрофии. Вагинальная атрофия становится клинически выраженной через 4-5 лет после наступления менопаузы и объективные изменения, также как и субъективные жалобы, отмечаются у $25-50 \%$ всех женщин в постменопаузе. Необходимо, чтобы гинекологи регулярно открыто и деликатно обсуждали с женщинами, которые находятся в периоде постменопаузы, состояние их мочеполовой системы с целью как можно раннего выявления постменопаузальной атрофии и обеспечения должного лечения. Лечение следует начинать на ранней стадии, прежде чем произойдут необратимые атрофические изменения. ЗГТ необходимо продолжать для сохранения положительного эффекта. Все местные препараты эстрогенов эффективны, и выбор метода лечения обычно зависит от предпочтений пациентки. Все доступные в настоящее время топические эстрогены всасываются; объем всасывания зависит от дозы и лекарственной формы. Дополнительное применение прогестагена не требуется в случае местного применения соответствующего низкодозированного эстрогена, хотя долгосрочных данных по этому вопросу (более 1 года) нет.

Данные о применении вагинальных эстрогенов у женщин с гинекологическими видами рака, реагирующего на гормоны, ограничены и, следовательно, при их использовании необходимо соблюдать осторожность. При мест- ном использовании эстрогенов у женщин, принимающих тамоксифен или ингибиторы ароматазы, необходимо провести тщательную консультацию и обсуждение с пациенткой всех онкологических рисков.

Что касается использования дополнительных методов лечения вазомоторных симптомов, то на данный момент в высококачественных исследованиях не было получено согласованных доказательств эффективности вспомогательных или безрецептурных препаратов в снижении тяжести либо частоты приливов или ночной потливости. А так называемые биоидентичные или естественные гормоны не имеют научного обоснования, позволяющего отмежевать их от множества зарегистрированных препаратов 3ГТ. Эстрадиол, эстрон или эстриол, синтезированные фармацевтически или приготовленные как «биоидентичные» препараты, обычно получают из растительного ямса и они идентичны эстрогенам яичников, но достаточных данных об их качестве, которые свидетельствовали бы о долгосрочной безопасности или эффективности какоголибо из этих препаратов, нет. Такие средства во многих странах не являются предметом внимательного изучения для фармацевтических регуляторных органов, и производители могут избежать контроля качества своих препаратов, тестирования их безопасности и эффективности.

\section{ЗГТ и сексуальность}

Сексуальность и качество жизни женщины в период менопаузы очень важны. Состояние здоровья является основным фактором, определяющим качество жизни, в особенности у пожилых людей, но сексуальные отношения также важны в любом возрасте. И возраст, и снижение уровня половых гормонов негативно влияют на половую функцию женщины, значительно усиливая сухость влагалища/диспареунию, существенно снижая желание и сексуальную чувствительность. Ослабленное либидо является наиболее распространенной жалобой в отношении секса у женщин. Однако есть возрастные изменения половых расстройств, связанные с индивидуальными нарушениями, которые особенно заметны у женщин с хирургической менопаузой. Таким женщинам угрожает повышенный риск гипоактивного расстройства сексуального желания. Женщины могут сами не начинать разговор о половом влечении, поведении и сексуальной активности, но они обычно ценят, если врач задает им этот вопрос. Применение ЗГТ оказывает положительное влияние на женскую сексуальHость.

\section{РИСКИ ЗГТ}

\section{Рак молочной железы (РМЖ)}

Частота рака в разных странах различна. Степень связи между применением ЗГТ в постменопаузальный период и развитием РМЖ остается спорной.

Женщин следует предупредить, что возможное повышение риска РМЖ, связанное с ЗГТ, невелико (менее 0,1\% в год, или частота $<1,0$ на 1000 женщин за год применения) в сравнении с повышенным риском, обусловленным обычными факторами образа жизни, такими как тучность и потребление алкоголя. Данные рандомизированного контролируемого исследования Women's Health Initiative (WHI) не свидетельствовали о повышении данного риска у 
пациенток, впервые прибегнувших к 3ГТ, в течение 5-7 лет с начала терапии. У большинства участниц исследования WHI отмечались избыток веса или тучность, что могло повлиять на исходный риск РМЖ.

Интересно, что одновременное резкое сокращение применения 3ГТ и снижение частоты РМЖ после проведения WHI в некоторых исследованиях было представлено как дальнейшее доказательство канцерогенных свойств эстрогенов. Однако недавно полученные данные свидетельствуют о повышении частоты РМЖ, несмотря на стабилизацию числа пациенток, прибегнувших к ЗГТ. Это указывает на то, что ЗГТ скорее может способствовать прогрессированию уже имеющейся опухоли молочной железы, нежели вызывать развитие рака.

Однако даже на сегодняшний день все еще недостаточно данных для оценки возможной разницы в частоте РМЖ в зависимости от различных типов, доз и путей введения эстрогенов, природного прогестерона, прогестагенов и андрогенов. Тем не менее, по данным масштабных европейских наблюдательных исследований, можно предположить, что разница в риске при монотерапии эстрогенами и применении комбинированной эстроген-прогестагеновой терапии отмечается только в случае некоторых категорий прогестагенов, а не производных природного прогестерона.

Следует все же помнить, что повышение плотности тканей на маммограмме в результате применения комбинированной эстроген-прогестагеновой терапии может осложнять диагностическую интерпретацию снимка.

\section{Рак эндометрия}

Отмечено, что продолжительное применение комбинации эстрогенов с прогестагенами сопровождается меньшей, чем в обычной популяции, частотой гиперплазии и рака эндометрия.

\section{Рак яичников}

Исследование WHI - это единственное РКИ, в котором рассматривался риск рака яичников при ЗГТ. На фоне комбинированной ЗГТ значительного повышения соответствующего риска не наблюдалось.

В целом, долгосрочная монотерапия эстрогенами может сопровождаться небольшим атрибутивным риском рака яичников, составляющим 0,7 на 1000 женщин за 5 лет применения, в то время как при использовании комбинации эстроген + прогестаген повышение риска значительно меньше либо вообще отсутствует.

\section{Колоректальный рак}

В большинстве наблюдательных исследований отмечено снижение риска колоректального рака у женщин на фоне применения пероральной ЗГТ.

Результаты трех мета-анализов свидетельствуют о снижении риска колоректального рака на фоне применения ЗГТ. Данный благоприятный эффект сохранялся в течение 4 лет после прекращения терапии. Типичным эффектом был уровень относительного риска (ОР), равный 0,80 (95\% доверительный интервал [ДИ] 0,74-0,86) у женщин, когдалибо применявших ЗГТ, и 0,66 (95\% ДИ 0,59-0,74) у женщин, применяющих ЗГТ в настоящее время.

Применение комбинации конъюгированных лошадиных эстрогенов + медроксипрогестерона ацетата в течение более 4 лет может снизить риск рака толстой кишки.

\section{Рак шейки матки}

В долгосрочных когортных исследованиях повышенного риска рака шейки матки на фоне применения ЗГТ не отмечено.

B PKИ WHI на фоне 3ГТ повышения риска рака шейки матки также не наблюдалось.

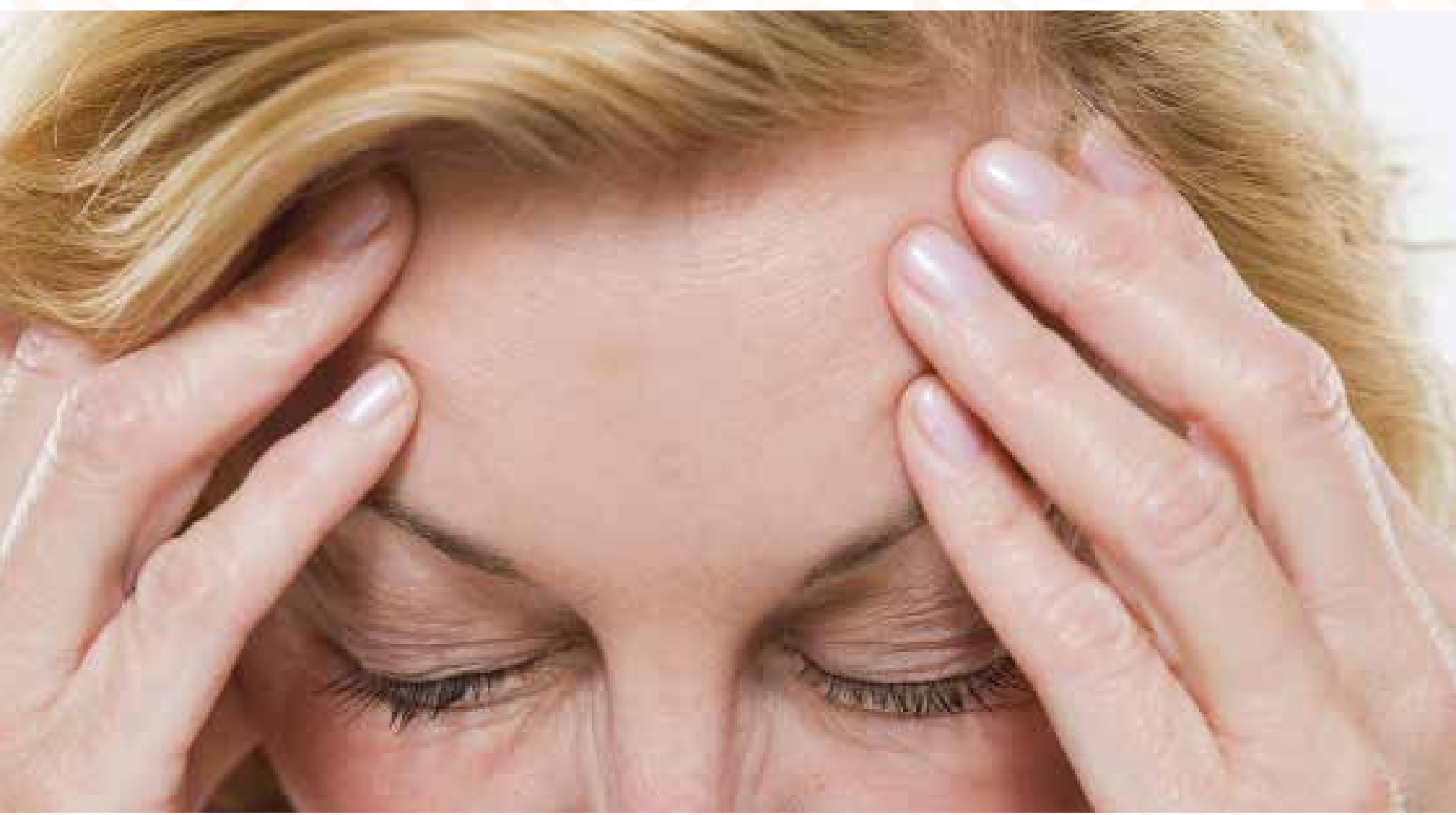




\section{Тромбоэмболия}

Пути введения препаратов определяют в некоторой степени безопасность применения 3ГТ, а именно риск венозной тромбоэмболии. При трансдермальном применении эстрадиола данный риск ниже, чем при оральном применении 3ГТ, благодаря отсутствию пресистемного печеночного метаболизма. Поступление прогестагенов в матку через влагалище обеспечивает необходимые локальные концентрации, хорошую защиту эндометрия, но приводит к очень низким системным концентрациям прогестагенов. В недавних наблюдательных исследованиях было показано, что трансдермальное введение эстрогена в постменопаузе не вызывает повышение риска сердечно-сосудистых осложнений, в частности инсульта и тромбоза вен. Но если говорить о риске серьезных венозных тромбоэмболических осложнений, обусловленных 3ГТ, то следует отметить, что этот риск, в первую очередь, увеличивается с возрастом (риск инсульта коррелирует с возрастом и редко случается у лиц моложе 60 лет), а также при наличии ожирения и тромбофилии. Соответственно, применение трансдермальных препаратов эстрогенов может позволить избежать риска, связанного с оральными путем введения гормонотерапии. Влияние на риск тромбоэмболических осложнений также может зависеть от типа прогестагена.

\section{ВЫВОДЫ}

ЗГТ в постменопаузальный период является частью общей стратегии медицинского наблюдения этой категории пациентов. Необходимо обязательно оценить пользу и риски ее применения, которые могут значительно отличаться в каждом отдельном случае. Проведенные в последнее десятилетие исследования помогли установить, что риски можно свести к минимуму, а пользу - к максимуму, выбрав оптимальную схему лечения в определенный период.

Требуются дальнейшие многоцентровые масштабные исследования по исследованию влияния 3ГТ на организм в целом с целью минимизации возможных рисков ее применения.

Необходим индивидуальный подход в выборе препаратов, режимов, доз и путей введения в каждом конкретном случае с вычислением конкретных рисков и ожидаемой пользы у каждой отдельной женщины, принимая во внимание возраст и преморбидный фон.

Следует воздержаться от курения.

> Изменения образа жизни включают участие в общественной жизни, физическую и умственную активность.

उГТ

Безопасность ЗГТ значительным образом зависит от возраста. Здоровые женщины моложе 60 лет не должны излишне беспокоиться о профиле безопасности ЗГТ.

Новые данные и повторные ре-

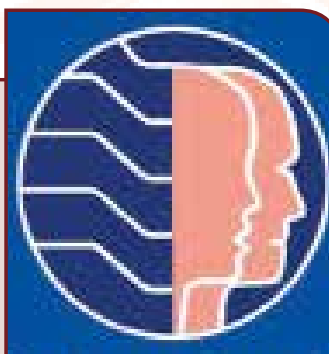
International Menopause Society wwwimsociety.org когнитивных функций и качества жизни. При этом кардиологические нарушения, инсульты, переломы, РМЖ и рак толстой кишки значительно менее часты.

- Польза от физических упражнений значительно перевешивает возможные неблагоприятные последствия: чем больше, тем лучше, однако излишняя активность может причинить вред.

Здоровый образ жизни

> Ожирение (индекс массы тела > 30 кг/м²) поражает более $20 \%$ популяции во многих странах мира и становится все более острой проблемой в нижних социоэкономических слоях, а также среди детей.

? Снижения веса всего на 5-10\% достаточно для нормализации многих отклонений, обусловленных синдромом резистентности к инсулину.

- Основными элементами здорового питания являются: потребление несколько раз в день фруктов и овощей, клетчатки цельного зерна, рыбы дважды в неделю и общее сокращение потребления жиров (но оливковое масло рекомендуется). Потребление соли рекомендуется сократить, а суточная порция алкоголя не должна превышать 30 г для мужчин и 20 г для женщин. зультаты анализа данных прошлых исследований с учетом возраста женщин показали, что в большинстве случаев потенциальные благоприятные эффекты ЗГТ многочисленны, а риски - наоборот, незначительны, если терапия начата в течение нескольких лет после начала менопаузы.

Что касается длительности применения ЗГТ, женщины могут применять ЗГТ до тех пор, пока она оказывает благоприятное действие на симптомы и пациентки осведомлены о рисках, связанных с их схемой лечения и личными обстоятельствами.

Таким образом, на сегодняшний день в арсенале современного врача имеется широкий ассортимент препаратов 3ГТ. Важность приема ЗГТ, основанная на данных доказательной медицины, связана не только с лечением климактерических расстройств, но и с профилактикой быстрого развития «заболеваний старости» - атеросклероза, остеопороза, артериальной гипертензии и др. Ограничений по длительности приема препаратов не существует. Длительность лечения определяется только патологией, по поводу которой были рекомендованы гормональные препараты. 


\section{ЛИТЕРATУPA/REFERENCES}

1. Татарчук Т.Ф., Ефименко О.А.

Современный взгляд на гормональную терапию // Репродуктивная эндокринология. -2012 . - № 2 (4). - С. 34-39.

Tatarchuk TF, Efimenko OA

Modern view at hormone therapy // Reproductive Endocrinology. - 2012. - №2 (4). - P.34-39.

2. Локшин В.Н., Петренко А.А., Арефьева Н.Е.

Влияние заболеваний репродуктивной системы на качество жизни женщин //

Российский вестник акушера-гинеколога. - 2005. - Т. 5, № 1. - С. 52-55.

Lokshin V, Petrenko A, Aref'eva NE

The impact of the reproductive system on the quality of women life // Russian Journal of the Obstetrician-Gynecologist. - 2005. - T. 5, № 1. - P. 52-55.

3. Татарчук Т.Ф., Ефименко О.А.

Принципи діагностики, профілактики та лікування клімактеричних розладів //

Журнал української лікарської еліти. - № 4 (10). - 2009. - С. $24-29$.

Tatarchuk TF, Efimenko OA

Diagnostics, prevention and treatment principles of menopausal disorders // Journal of Ukrainian Medical Elite. - № 4 (10). - 2009. - P. 24-29.

4. Сметник В.П.

Медицина климактерия. - М., 2006. - 848 с.

Smetnik VP

Medical menopause. - M., 2006. -848 p.

5. Scheider HPG, Heinemann LAJ, Rosemeir HP et al.

The menopause rating scale (MRS): reliability of scores of menopausal compleants //

Climacteric. - 2000. - Vol. 3. - P. 59-64.
6. Татарчук Т.Ф., Косей Н.В., Самосийна О.А., Зданович И.Е. Можливості застосування гормоновальної терапії в лікуванні важкої форми клімактеричного синдрому у жінок з лейоміомою матки // Здоровье женщины. - № 6 (52). - 2010. - С. 118-121.

Tatarchuk TF, Cossey NV, Samosiyna OA, Zdanowicz IE Hormonal therapy in the treatment of severe climacteric syndrome in women with uterine leiomyomas // Women Health. - № 6 (52). - 2010. - P. 118-121.

7. Update IMS recommendations on postmenopausal hormone therapy and preventive strategies for medlife health.

International menopause society. $-2011 .-25 \mathrm{p}$.

8. Lole Di Francesc

Menopause State of the art. $-2011 .-540 p$.

9. Lobo RA

Metabolic syndrome after menopause and the role of hormones. 60 (1): 10-8, 2008.

10. Mendelsohn ME, Karas RH

Science 308, 1583 (2005).

11. Rossouw JE

Cardiovascular Research 53 (2002): 550-557.

12. Margolis K et al.

Diabetologia 2004; 47: 1175-87.

13. Bonds DE et al.

Diabetologia 2006; 49: 459-468.

\section{МЕНОПАУЗА: НОВИЙ ПОГЛЯД НА СТАРУ ПРОБЛЕМУ}

Т.Ф. Татарчук, д.мед.н., професор, член-корр. НАМН України, заступник директора з наукової роботи, завідувачка відділення ендокринної гінекології Інституту педіатрії, акушерства та гінекології НАМН України

О.А. Єфименко, к.мед.н., старший науковий співробітник відділення ендокринної гінекології Інституту педіатрії, акушерства та гінекології НАМН України

А.О. Ісламова, к.мед.н., відділення ендокринної гінекології Інституту педіатрії, акушерства та гінекології НАМН України

У статті представлено основні принципи Рекомендацій Міжнародного товариства менопаузи з використання замісної гормональної терапії (2011), а також описано основну користь та ризики призначення замісної гормональної терапії.

Безпека замісної гормональної терапії значною мірою залежить від віку. Здорові жінки віком до 60 років не повинні надмірно турбуватися про безпеку замісної гормональної терапії. у більшості випадків потенційні сприятливі ефекти замісної гормональної терапії численні, а ризики незначні, якщо терапію розпочато протягом кількох років після початку менопаузи.

Що стосується тривалості застосування замісної гормональної терапії, то жінки можуть застосовувати замісну гормональну терапію доти, поки вона має сприятливу дію на симптоми і пацієнтки обізнані про можливі ризики.

Ключові слова: замісна гормональна терапія, рекомендації, Міжнародне товариство менопаузи.

\section{MENOPAUSE: A NEW LOOK AT AN OLD PROBLEM}

T.F. Tatarchuk, MD, professor, corresponding member of NAMS of Ukraine, Deputy Director for Research Work, Chief of the Endocrine Gynecology Department, SI «Institute of Pediatrics, Obstetrics and Gynecology, NAMS of Ukraine»

O.A. Yefimenko, PhD, senior researcher of the Endocrine Gynecology Department, Institute of Pediatrics, Obstetrics and Gynecology NAMS of Ukraine

A.O. Islamova, PhD, Endocrine Gynecology Department, Institute of Pediatrics, Obstetrics and Gynecology NAMS of Ukraine

The article presents the basic principles of the International Menopausal Society Guidelines on the hormone replacement therapy (2011), and describes the main benefits and risks of hormone replacement therapy.

Safety of hormone replacement therapy largely depends on age. Healthy women younger than 60 years should not be overly concerned about the safety of hormone replacement therapy. If hormone replacement therapy is initiated within a few years after menopause, the potential beneficial effects of it are numerous and risks are minor in most cases.

Women can use hormone replacement therapy as long as it has a beneficial effect on the symptoms and the patient aware of the possible risks.

Keywords: hormone replacement therapy, recommendations, International Menopause Society. 